\title{
Clinical Results and Complications of Shoulder Manipulation under Ultrasound-Guided Cervical Nerve Root Block for Frozen Shoulder: A Retrospective Observational Study
}

\author{
Ryosuke Takahashi · Yusuke Iwahori · Yukihiro Kajita • \\ Yohei Harada · Yoshitaka Muramatsu • Tatsunori Ikemoto • \\ Masataka Deie
}

Received: September 21, 2018 / Published online: February 11, 2019

(C) The Author(s) 2019

\section{ABSTRACT}

Introduction: Manipulation under ultrasoundguided fifth and sixth cervical nerve root block (MUC) is a recognized form of treatment for patients with persistent frozen shoulder (FS). This study aimed to investigate the confirmatory hypothesis testing that the MUC has a significant clinical effect on FS refractory to conservative treatments and to assess its adverse events.

Methods: This is a retrospective observational study on patients with FS treated in the past 8 years. Although 77 patients were eligible for this study, only 68 were enrolled. The patients were evaluated immediately before the MUC and at 1 , 3 , and 6 months after with the use of the Japanese Orthopaedic Association shoulder score. Simultaneously, ranges of motion of the affected shoulder were measured in two directions: forward flexion and external rotation. A paired $t$ test or a Wilcoxon signed-rank test was used to compare differences in outcomes between before and 6 months after MUC. We also assessed any adverse events during and after the MUC.

Enhanced Digital Features To view enhanced digital features for this article go to: https://doi.org/10.6084/ m9.figshare.7472420.

R. Takahashi $(\bowtie) \cdot$ Y. Iwahori · Y. Kajita .

Y. Harada · Y. Muramatsu · T. Ikemoto · M. Deie Department of Orthopedic Surgery, Aichi Medical University, Nagakute, Aichi, Japan

e-mail: takahashi.ryosuke0617@gmail.com
Results: Regarding the primary outcome, confirmatory testing showed statistically significant improvements in every outcome value at 6 months after MUC $(p<0.001)$. In terms of adverse events, two patients $(2.9 \%)$ had vasovagal reflex, one $(1.5 \%)$ had a panic attack during the block procedure, and a 72-year-old female patient $(1.2 \%)$ had an avulsion fracture of the inferior glenoid during the manipulation procedure, although all of them recovered spontaneously without any residual functional impairment.

Conclusion: The results showed that significant clinical effects of the MUC on FS were observed through a confirmatory analysis with a sufficient sample size. However, several complications that could occur during the block and manipulation procedures should be considered.

Keywords: Adhesive capsulitis; Cervical nerve root block; Frozen shoulder; Manipulation

\section{INTRODUCTION}

Frozen shoulder (FS) or adhesive capsulitis is one of the most common orthopedic conditions affecting the shoulder, with prevalence of $2-5 \%$ in the general population [1-3]. This condition commonly occurs between 40 and 60 years of life, with the peak age in the mid-50s [4]. Although FS was generally thought to resolve in 2-3 years, a recent study indicated that pain and limitation of movement could persist for much 
longer than these periods [4]. FS is classically described as a benign condition consisting of three stages: painful freezing, adhesive or frozen, and the thawing or recovery phase. Many patients experienced persistent pain accompanied with limited range of motion (ROM) $[1,4]$.

However, the treatment of FS remains controversial despite the many previous studies $[5,6]$. Although conservative treatments, such as nonsteroidal anti-inflammatory drugs (NSAIDs) [4-8], [9, 20, 21], intra-articular corticosteroid injection [4-6, 9-11], physical therapy [4-6, 12-14], watchful neglect [15], and hydrodilatation [16-18], are generally preferred, manipulation under anesthesia $[4,19-23]$ or surgical treatments such as arthroscopic capsular release [24-27] can be performed in cases of persistent pain and long-term limited ROM.

Manipulation under ultrasound-guided fifth and sixth cervical nerve root block (MUC) is a recognized form of treatment for patients with persistent FS. Minagawa reported the efficacy of shoulder manipulation following the MUC as an outpatient procedure in Japan [28]. Since MUC facilitates avoidance of blood vessels near the target nerves through visualization [29-31], this procedure has been established as a safe and effective way to ameliorate pain and ROM in patients with persistent FS [32, 33]. Saito et al. have recently reported that the MUC for FS refractory to conservative treatments resulted in good clinical outcomes for at least 1-year follow-up. However, the study recruited a small number of patients with FS [33], and several complications have to be considered in a large sample. Thus, a confirmatory study using a large sample should be conducted to validate the efficacy and safety of the MUC procedure.

Therefore, this study aimed to investigate the confirmatory hypothesis testing that the MUC procedure has a significant clinical effect on FS refractory to conservative treatments and to assess its adverse events.

\section{METHODS}

\section{Study Participants}

The sample size was estimated based on a hypothesis that a small-to-medium effect size
(Cohen's $d=0.4$ ) [34] could be expected to improve the Japanese Orthopaedic Association (JOA) shoulder score at 6-month follow-up after the MUC procedure. Based on this assumption, the sample size for a power of $>0.90$ with a twotailed alpha at a significance level of $<0.05$ to run a $t$ test (matched pair) required a minimum of 68 patients [35].

Patients (1) who were diagnosed with FS refractory to conservative treatments such as oral NSAIDs, intra-articular corticosteroid injection, and physical therapy for at least 6 months, (2) who had limited shoulder ROM in at least two directions, i.e., forward flexion of $\leq 100^{\circ}$ and external rotation at the side of $\leq 10^{\circ}$ [33], and (3) who were followed up for at least 6 months after the MUC procedure were included in this study.

On the contrary, patients with rotator cuff tear, shoulder osteoarthritis, calcified tendinitis, long head of biceps tendon injury, hemiplegia after stroke, bone metastasis in the shoulder region, history of shoulder fractures, or history of shoulder surgeries were excluded.

Although 77 patients were eligible for this study and all of them underwent the MUC procedure, some could not be followed up until 6 months later. Thus, only 68 patients were finally enrolled (Table 1).

Table 1 Patient's demographics at baseline

\begin{tabular}{ll}
\hline Variables & \\
\hline Age (years) & $52.0[38-72](7.5)$ \\
Gender & $26[38.2 \%] / 42[61.8 \%]$ \\
Male/female (\%) & \\
Affected side & $25[36.8 \%] / 43[63.2 \%]$ \\
Dominant/non-dominant $(\%)$ & $23[17.7-35]$ \\
Body mass index $\left(\mathrm{kg} / \mathrm{m}^{2}\right)$ & $15[22.1 \%]$ \\
Presence of diabetes $(\%)$ &
\end{tabular}

Continuous data are shown as the mean (SD) or the median [range] 


\section{Manipulation Procedure and Post-MUC Therapy}

All procedures were performed in the same manner (Fig. 1); however, patients were treated by either one of the two skilled surgeons (Y.I. or Y.K.). The MUC was performed in an outpatient setting. The patient was placed in a supine position; the cervical nerve roots (C5 and C6) between the anterior and middle scalene muscles were identified using an ultrasound guide (SNiBLE, Konica Minolta, Tokyo, Japan), and then $15-20 \mathrm{ml}$ of $1 \%$ lidocaine was injected around the C5/C6. Manipulation was started after evaluating immediate procedural complications and confirming the absence of pain around the shoulder joint at passive forward flexion and abduction.

Manipulation was first performed at external rotation (Fig. 1a) to complete the tearing of the anterior capsule and then at forward flexion to complete the inferior capsule tear (Fig. 1b).
Next, external rotation with the arm at the side and at $90^{\circ}$ abduction on the scapula plane was performed to complete the anterior and inferior capsule tears (Fig. 1c). Finally, internal rotation with the arm at $90^{\circ}$ abduction on the scapula plane to complete the posterior and inferior capsule tear (Fig. 1d) and at extension until the vertebral height of the patient's dominant thumb to complete the anterior and superior capsule was performed (Fig. 1e).

After completing the MUC, we checked the patient's vital signs and injected $10 \mathrm{ml} 1 \%$ lidocaine and $2.5 \mathrm{mg}$ corticosteroid into the glenohumeral joint to prevent postprocedural pain.

The day after the MUC, we performed radiographic assessments to confirm major complications such as pneumothorax and humeral fracture and also checked for neurologic and vascular injuries. If no complications were noted, patients were encouraged to continue the shoulder rehabilitation program such
A

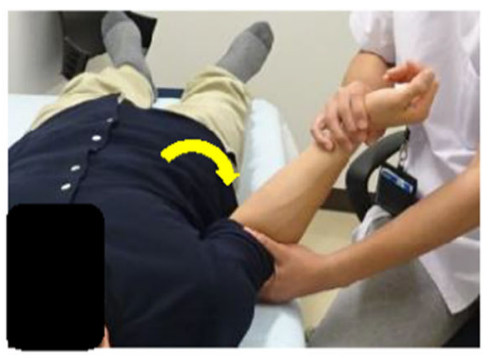

B

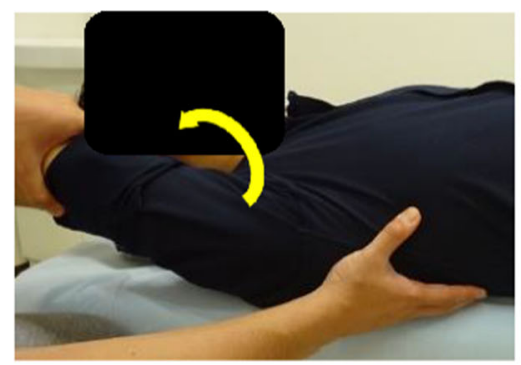

C

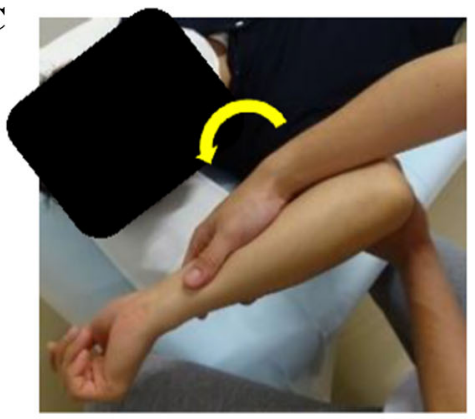

D

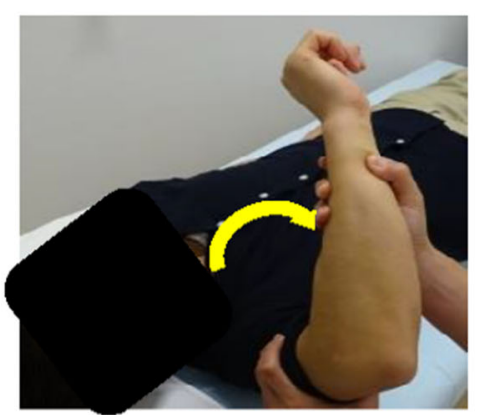

$\mathbf{E}$

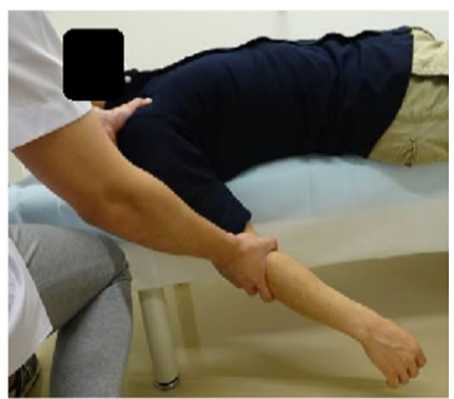

Fig. 1 Manipulation procedure. a External rotation with the arm at the side to complete the tearing of the anterior capsule. b Forward flexion to complete the inferior capsule tear. $\mathbf{c}$ External rotation with the arm at $90^{\circ}$ abduction on the scapula plane to complete the anterior and inferior capsule tears. d Internal rotation with the arm at $90^{\circ}$ abduction on the scapula plane to complete the posterior and inferior capsule tears. e Extension and internal rotation until the vertebral height of the patient's dominant thumb to complete the anterior and superior capsules 
as passive and active ROM exercises for the next 3 months. Patients were also allowed to use analgesic drugs as necessary.

\section{Clinical Assessments}

All of the patients were evaluated immediately before the MUC (baseline) and at 1, 3, and 6 months after with the use of the JOA shoulder score, which consisted of the level of shoulder pain, function, ROM, radiographic findings, and joint stability, ranging from 0 to 100 points. Probable maximum scores for each subcategory were 30 points for pain, 20 for function, 30 for ROM, 5 for radiographic findings, and 15 for joint stability, with higher scores indicating better outcome [36]. We also measured ROMs of the affected shoulder in two directions at the same time: forward flexion and external rotation.

We investigated the following potential variables: age, gender, affected side (dominant or non-dominant), body mass index (BMI), and presence of diabetes, which were possible factors associated with the severity of symptoms in patients with FS. BMI was calculated based on these values using the following formula: BMI $=$ weight $(\mathrm{kg}) /$ height $\left(\mathrm{m}^{2}\right)$. The mean period of diabetes was 10 years [range 5-20].

Furthermore, we assessed any adverse events during and after the MUC.

\section{Statistical Analysis}

Continuous data were presented as the mean and standard deviation (SD) in normal distribution or as median and ranges $[X$ to $Y]$ in nonnormal distribution. The Shapiro-Wilk test was used to investigate whether the data were normally distributed. A paired t-test or a Wilcoxon signed-rank test was used to compare differences in each outcome between the baseline and 6 months after the procedure as appropriate. Although the statistical significance was set as $p<0.05, p<0.017$ was considered significant after a Bonferroni correction, because three outcome variables were used to evaluate the efficacy of the MUC.
We also used a repeated measure analysis of variance or a Friedman test to evaluate each outcome at every follow-up point: baseline, 1, 3, and 6 months after the procedure. If these analyses demonstrated a significant chronologic effect, multiple comparison was performed using the Scheffé method, and statistical significance was set as $p<0.05$.

Subsequently, we determined five independent variables: age, gender, affected side, BMI, and presence of diabetes, which were possible factors associated with the JOA shoulder score at baseline. A stepwise multiple linear regression was conducted to determine which independent variables best correlated with the recovery rate, and statistical significance was set as $p<0.05$. All of these analyses were conducted using IBM SPSS ${ }^{\circledR} 25.0$ software for Windows ${ }^{\circledR}$ (IBM Inc.).

\section{Study Design and Ethical Approval}

The study was approved by the ethical committee at Aichi Medical University and performed in accordance with the 1964 Helsinki declaration and its later amendments. Due to the retrospective nature of the study design, written consent form of the study was waived for patients treated during the study period unless they refused to provide the information in accordance with the opt-out strategy.

\section{RESULTS}

Among the patients who underwent the MUC procedure, 11 had dropped out during the 6-month follow-up period. Patient demographics at baseline are shown in Table 1 . The mean age of patients was 52.0 years, the number of females was approximately two times that of males, and the dominant limb was involved approximately twice as often as that of the nondominant limb. In the correlation analysis, we found that the predicted variables were not significantly correlated with the JOA score at baseline (Table 2 ).

Regarding the primary outcome, the confirmatory testing showed statistically significant improvements in every outcome value at 
Table 2 Spearman's correlation coefficients between each variable and the JOA shoulder score at baseline

\begin{tabular}{lcclrr}
\hline & Age & $\begin{array}{l}\text { Gender (1: male, 2: } \\
\text { female) }\end{array}$ & $\begin{array}{l}\text { Affected side (1: dominant, 2: non- } \\
\text { dominant })\end{array}$ & BMI & Diabetes \\
\hline $\begin{array}{l}\text { JOA shoulder } \\
\text { score }\end{array}$ & 0.078 & -0.066 & -0.070 & -0.107 & -0.144 \\
\begin{tabular}{l}
$p$ value \\
\hline
\end{tabular} & 0.53 & 0.59 & 0.57 & 0.38 & 0.24 \\
\hline
\end{tabular}

6 months after the MUC compared with those at baseline (Fig. 2). The JOA shoulder scores showed a significant improvement from 58.4 (8.1) at baseline to $92.6(8.2)$ and 95 [63-100] at 6-month follow-up $(p<0.001)$. The degrees of ROMs in forward flexion and external rotation also showed significant improvement from 90 [60-90] and 10 [5-15] at baseline to 167.5 [80-180] and 42.5 [0-70] at 6-month follow-up, respectively $(p<0.001, p<0.001)$.

Time series analysis also indicated that each outcome value displayed a chronologic improvement (Table 3).

In terms of adverse events, two patients (2.9\%) had vasovagal reflex and one (1.5\%) had a panic attack during the block procedure, resulting in full recovery after several hours without treatment and returned home on the same day. Regarding the complication related to manipulation, a 72-year-old female patient $(1.2 \%)$ had an avulsion fracture of the inferior glenoid rim during the manipulation that healed spontaneously without any residual functional impairment.

\section{DISCUSSION}

This study hypothesized that the MUC had a significant clinical effect on FS refractory to at least 6-month conservative treatments, and we confirmed that significant chronologic effects of the MUC on FS were observed through a confirmatory analysis with a sufficient sample size. In contrast, the study also considered that several complications could occur during the block and manipulation procedures even if performed by skilled surgeons.

Early recovery from FS is essential to improve an individual's quality of life. Although its pathogenesis has been described as inflammatory thickening of the articular capsule, the
Forward flexion

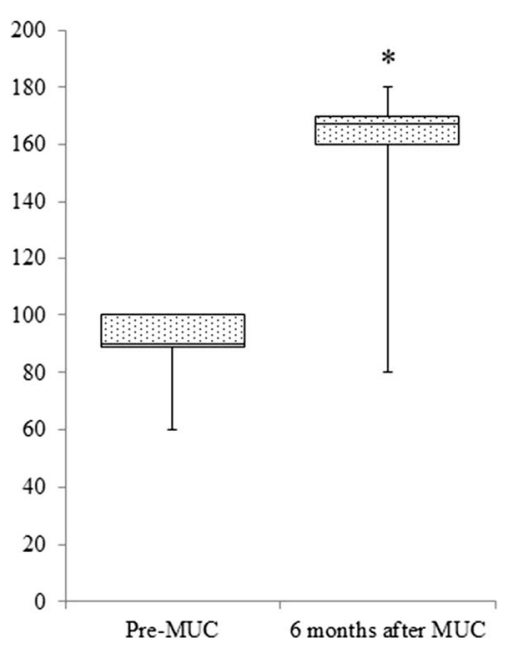

External rotation

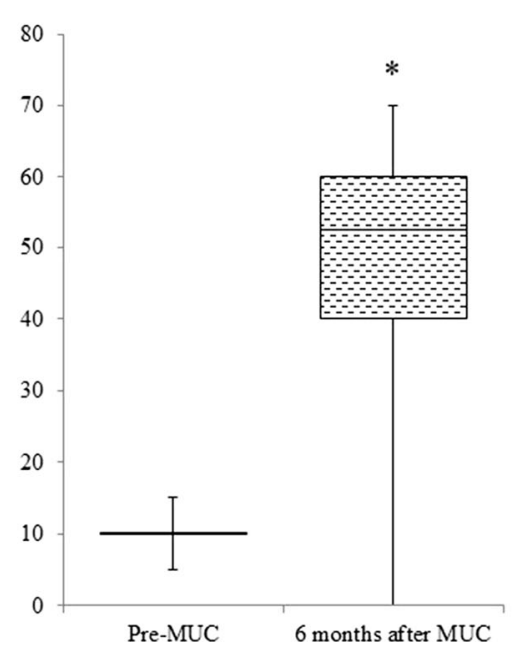

JOA shoulder score

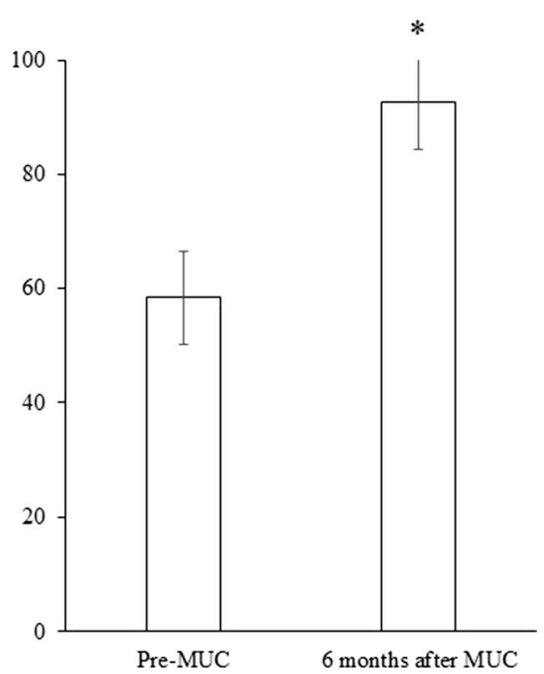

Fig. 2 Each outcome value at pre-MUC and 6 months after MUC 
Table 3 Changes in each parameter from baseline to follow-ups over a 6-month period

\begin{tabular}{|c|c|c|c|c|}
\hline & \multirow[t]{2}{*}{ Pre MUC } & \multicolumn{3}{|l|}{ After MUC } \\
\hline & & 1 month & 3 months & 6 months \\
\hline JOA shoulder score (point) & $58.4(8.1)$ & $85.5[57-100]^{*}$ & $89.5[60-100]^{*,}$ & $95[63-100]^{*, 5}$ \\
\hline Degree of forward flexion $\left(^{\circ}\right)$ & $90[60-100]$ & $150[70-180]^{*}$ & $160[90-180]^{* \$}$ & $167.5[80-100]^{*, S}$ \\
\hline Degree of external rotation $\left({ }^{\circ}\right)$ & $10[5-15]$ & $42.5[0-70]^{*}$ & $50[0-70]^{* \S}$ & $52.5[0-70]^{*, \S}$ \\
\hline
\end{tabular}

Continuous data are shown as the mean (SD) or the median [range]

Symbols indicate significant difference in each value by Scheffé comparison $(p<0.05)$; *vs. pre-MUC, ${ }^{\$}$ vs. 1 month after MUC, ${ }^{\top}$ vs. 3 months after MUC

development of intra- or extra-articular synovial inflammation [37, 38], a consistent mechanism of ROM restriction, remains unclear. Although FS was generally thought to resolve in 2-3 years, a recent study indicated that pain and limitation of movement could persist for much longer than these periods [4]. Aging, female gender, non-dominant shoulder, and increased BMI have been reported to be likely associated with FS [4, 39]; moreover, diabetes is one of the dominant diseases associated with FS $[4,39,40]$. However, only $22.1 \%$ of the patients had diabetes in this study; therefore, the JOA score was not statistically associated with the presence of diabetes. This result could be caused by sample selection bias, because a trend of mild correlation $(r=-0.14)$ was observed between the two parameters.

The MUC has been suggested and performed with satisfactory results. In addition, the pros and cons of the block method will also be discussed here. Pobiel et al. have reported complications of fluoroscopic-guided interscalene brachial plexus block (ISB) such as hematoma by vascular puncture, pneumothorax, spinal cord insult, and nerve root deficit [41]. Although uncommon, ISB can result in devastating results [42, 43]. An ultrasound-guided approach could prevent these complications through continuous visualization of the treatment site through real-time images during the block procedure. This method is also helpful to prevent both physicians and patients from external radiation exposure. However, an ultrasound-guided approach requires precise knowledge on the association between real anatomical structures and ultrasound reflecting structures; thus, long-standing experience is needed.

Although major complications were not observed in our study, two patients had vasovagal reflex and one had a panic attack during the block procedure. Pobiel et al. have reported minor complications that could occur within 30 min of the block procedure [41]. Although these are nonspecific symptoms and generally do not require specific treatment, vasovagal reactions and sympathetic blockade are prevalent in this block [41]. Three minor complications $(3.9 \%)$ were observed in our study, and the rate of incidence was consistent with that of the previous report [41]. Therefore, physicians should be aware of these minor complications during the block procedure.

Surgeons should also consider the complications of shoulder manipulation. Sasanuma et al. reported that magnetic resonance imaging (MRI) in patients with severe FS after MUC showed capsule tears, labrum tears, and bone bruises in the humeral head, and approximately $50 \%$ of patients had bone bruises [32]. Major complications, such as rotator cuff injury, humeral fracture, shoulder dislocation, and traction nerve injury, seldom occur [44, 45]. Magnussen described in a case report that a glenoid fracture is associated with manipulation under anesthesia for adhesive capsulitis [46], and Vastamaki et al. also described two inferior glenoid rim fractures [23]. In this study, a 72-year-old female patient who was not assessed for bone vulnerability had an avulsion fracture of the inferior glenoid rim after manipulation. This implies that we should assess the degree of osteoporosis prior to the procedure and perform 
a particularly meticulous procedure in elderly female patients.

Altogether, manipulation under anesthesia for FS is a relatively safe and effective procedure; thus, surgeons who perform it should be aware of and alert patients on potential complications because a capsular release technique always has potential tissue insults.

There are several limitations to our study. First, although this study showed a significant effect of the MUC on FS refractory to at least 6-month conservative treatment, no controls were set. As the patients had suffered from pain and disabilities for at least 6 months, continuing general therapy was difficult. Thus, the degree of superiority of MUC compared with other treatments or the natural course is unknown.

Second, psychologic disorders have been reportedly associated with shoulder pain and restrictions in patients with FS [47]; however, this study did not include psychologic assessments.

Third, although the clinical stage of FS was not assessed at baseline, this may have affected the results. Fourth, we did not evaluate MRI after MUC; however, several tissue insults could be found such as bone bruises if screening MRI was performed for each case. Lastly, although diabetes was not associated with disease severity at baseline among this sample, other relevant comorbidities such as thyroid disorders and hyperlipidemia should have been assessed as well $[39,48]$. Rigorous studies utilizing appropriate methodologies could clarify the clinical significance of the MUC on FS refractory to conservative treatments.

\section{CONCLUSION}

This study hypothesized that the MUC had a significant clinical effect on FS refractory to at least 6-month conservative treatment, and we confirmed that significant chronologic effects of the MUC on FS were observed through confirmatory analysis with a sufficient sample size. However, two patients $(2.4 \%)$ had a vasovagal reflex, one (1.1\%) had a panic attack, and one (1.1\%) had an avulsion fracture of the inferior glenoid rim. The
MUC for FS is a relatively safe and effective procedure; thus, surgeons who perform it should be aware of and alert patients to potential complications because a capsular release technique always has potential tissue insults.

\section{ACKNOWLEDGEMENTS}

We thank the study participants.

Funding. No funding or sponsorship was received for this study or publication of this article.

Authorship. All named authors meet the International Committee of Medical Journal Editors (ICMJE) criteria for authorship for this article, take responsibility for the integrity of the work as a whole, and have given their approval for this version to be published.

Disclosures. Ryosuke Takahashi, Yusuke Iwahori, Yukihiro Kajita, Yohei Harada, Yoshitaka Muramatsu, Tatsunori Ikemoto, and Masataka Deie have nothing to disclose.

Compliance with Ethics Guidelines. The study was approved by the ethical committee at Aichi Medical University and performed in accordance with the 1964 Helsinki declaration and its later amendments. Due to the retrospective nature of the study design, written consent form of the study was waived for patients treated during the study period unless they refused to provide the information in accordance with the opt-out strategy.

Data Availability. The data sets generated during and/or analyzed during the current study are available from the corresponding author on reasonable request.

Open Access. This article is distributed under the terms of the Creative Commons Attribution-NonCommercial 4.0 International License (http://creativecommons.org/licenses/ by-nc/4.0/), which permits any noncommercial use, distribution, and reproduction in any medium, provided you give appropriate 
credit to the original author(s) and the source, provide a link to the Creative Commons license, and indicate if changes were made.

\section{REFERENCES}

1. Reeves B. The natural history of the frozen shoulder syndrome. Scand J Rheumatol. 1975;4(4):193-6.

2. Morén-Hybbinette I, Moritz U, Scherstén B. The clinical picture of the painful diabetic shouldernatural history, social consequences and analysis of concomitant hand syndrome. Acta Med Scand. 1987;221(1):73-82.

3. Zreik NH, Malik RA, Charalambous CP. Adhesive capsulitis of the shoulder and diabetes: a metaanalysis of prevalence. Muscles Ligaments Tendons J. 2016;6(1):26-34.

4. Dias R, Cutts S, Massoud S. Frozen shoulder. BMJ. 2005;331(7530):1453-6.

5. Maund E, Craig D, Suekarran S, Neilson A, Wright $\mathrm{K}$, Brealey S, et al. Management of frozen shoulder: a systematic review and cost-effectiveness analysis. Health Technol Assess. 2012;16(11):1-264.

6. Page MJ, Green S, Kramer S, Johnston RV, McBain B, Chau M, et al. Manual therapy and exercise for adhesive capsulitis (frozen shoulder). Cochrane Database Syst Rev. 2014;8:CD011275.

7. Ohta S, Komai O, Hanakawa H. Comparative study of the clinical efficacy of the selective cyclooxygenase- 2 inhibitor celecoxib compared with loxoprofen in patients with frozen shoulder. Mod Rheumatol. 2014;24(1):144-9.

8. Duke O, Zecler E, Grahame R. Anti-inflammatory drugs in periarthritis of the shoulder: a doubleblind, between-patient study of naproxen versus indomethacin. Rheumatol Rehabil. 1981;20(1):54-9.

9. Buchbinder R, Hoving JL, Green S, Hall S, Forbes A, Nash P. Short course prednisolone for adhesive capsulitis (frozen shoulder or stiff painful shoulder): a randomised, double blind, placebo controlled trial. Ann Rheum Dis. 2004;63(11):1460-9.

10. Ryans I, Montgomery A, Galway R, Kernohan WG, McKane R. A randomized controlled trial of intraarticular triamcinolone and/or physiotherapy in shoulder capsulitis. Rheumatology (Oxford). 2005;44(4):529-35.
11. Binder A, Hazleman BL, Parr G, Roberts S. A controlled study of oral prednisolone in frozen shoulder. Br J Rheumatol. 1986;25(3):288-92.

12. Green S, Buchbinder R, Hetrick S. Physiotherapy interventions for shoulder pain. Cochrane Database Syst Rev. 2003;2:CD004258.

13. Sokk J, Gapeyeva H, Ereline J, Kolts I, Paasuke M. Shoulder muscle strength and fatigability in patients with frozen shoulder syndrome: the effect of 4 -week individualized rehabilitation. Electromyogr Clin Neurophysiol. 2007;47(4-5):205-13.

14. Russell S, Jariwala A, Conlon R, Selfe J, Richards J, Walton M. A blinded, randomized, controlled trial assessing conservative management strategies for frozen shoulder. J Shoulder Elb Surg. 2014;23(4):500-7.

15. Diercks RL, Stevens M. Gentle thawing of the frozen shoulder: a prospective study of supervised neglect versus intensive physical therapy in seventy-seven patients with frozen shoulder syndrome followed up for two years. J Shoulder Elb Surg. 2004;13(5):499-502.

16. Mun SW, Baek CH. Clinical efficacy of hydrodistention with joint manipulation under interscalene block compared with intra-articular corticosteroid injection for frozen shoulder: a prospective randomized controlled study. J Shoulder Elb Surg. 2016;25(12):1937-43.

17. Quraishi NA, Johnston P, Bayer J, Crowe M, Chakrabarti AJ. Thawing the frozen shoulder. A randomised trial comparing manipulation under anaesthesia with hydrodilatation. J Bone Joint Surg Br. 2007;89(9):1197-200.

18. Yoon JP, Chung SW, Kim HS, Lee HJ, Jeong WJ, et al. Intra-articular injection, subacromial injection, and hydrodilatation for primary frozen shoulder: a randomized clinical trial. J Shoulder Elb Surg. 2016;25(3):376-83.

19. Dodenhoff RM, Levy O, Wilson A, Copeland SA. Manipulation under anesthesia for primary frozen shoulder: effect on early recovery and return to activity. J Shoulder Elb Surg. 2000;9(1):23-6.

20. Amir-Us-Saqlain H, Zubairi A, Taufiq I. Functional outcome of frozen shoulder after manipulation under anaesthesia. J Pak Med Assoc. 2007;57(4):181-5.

21. Farrell CM, Sperling JW, Cofield RH. Manipulation for frozen shoulder: long-term results. J Shoulder Elb Surg. 2005;14(5):480-4.

22. Thomas WJ, Jenkins EF, Owen JM, Sangster MJ, Kirubanandan R, Beynon C, et al. Treatment of 
frozen shoulder by manipulation under anaesthetic and injection: does the timing of treatment affect the outcome? J Bone Joint Surg Br. 2011;93(10):1377-81.

23. Vastamaki H, Vastamaki M. Motion and pain relief remain 23 years after manipulation under anesthesia for frozen shoulder. Clin Orthop Relat Res. 2013;471(4):1245-50.

24. Conti V. Arthroscopy in rehabilitation. Orthop Clin North Am. 1979;10(3):709-11.

25. Snow M, Boutros I, Funk L. Posterior arthroscopic capsular release in frozen shoulder. Arthroscopy. 2009;25(1):19-23.

26. Le Lievre HM, Murrell GA. Long-term outcomes after arthroscopic capsular release for idiopathic adhesive capsulitis. J Bone Joint Surg Am. 2012;94(13):1208-16.

27. Miyazaki AN, Santos PD, Silva LA, Sella GD, Carrenho L, Checchia SL. Clinical evaluation of arthroscopic treatment of shoulder adhesive capsulitis. Rev Bras Ortop. 2017;52(1):61-8.

28. Minagawa H. Ultrasound medical care in practice for shoulder contracture [in Japanese]. Jpn J Orthop Rehabil. 2011;14:6-9.

29. Park Y, Ahn JK, Sohn Y, Jee H, Lee JH, Kim J, et al. Treatment effects of ultrasound guide selective nerve root block for lower cervical radicular pain: a retrospective study of 1-year follow-up. Ann Rehabil Med. 2013;37(5):658-67.

30. Narouze SN, Vydyanathan A, Kapural L, Sessler DI, Mekhail N. Ultrasound-guided cervical selective nerve root block: a fluoroscopy-controlled feasibility study. Reg Anesth Pain Med. 2009;34(4):343-8.

31. Pobiel RS, Schellhas KP, Eklund JA, Golden MJ, Johnson BA, Chopra S, et al. Selective cervical nerve root blockade: prospective study of immediate and longer term complications. AJNR Am J Neuroradiol. 2009;30(3):507-11.

32. Sasanuma H, Sugimoto H, Kanaya $Y$, et al. Magnetic resonance imaging and short-term clinical results of severe frozen shoulder treated with manipulation under ultrasound-guided cervical nerve root block. J Shoulder Elb Surg. 2016;25(1):e13-20.

33. Saito T, Sasanuma H, Iijima Y, et al. Short-term clinical results of frozen shoulder treated with shoulder manipulation under ultrasound-guided cervical nerve root block at outpatient setting: a case series. J Orthop Sci. 2017;22(2):275-80.
34. Cohen J. Statistical power analysis for the behavioral sciences. Hillsdale: Lawrence Erlbaum Associates; 1988.

35. Faul F, Erdfelder E, Buchner A, Lang AG. Statistical power analyses using G*Power 3.1: tests for correlation and regression analyses. Behav Res Methods. 2009;41:1149-60.

36. Kawakami J, Gotoh M, Matsuura K, Shin K, Fujito I, Tanaka A, et al. Cut-off values of the Japanese Orthopaedic Association score corresponding to Constant scores for evaluating outcomes in rotator cuff tear. J Orthop Surg Hong Kong. 2017;25(2):2309499017720002.

37. Rodeo SA, Hannafin JA, Tom J, Warren RF, Wickiewicz TL. Immunolocalization of cytokines and their receptors in adhesive capsulitis of the shoulder. J Orthop Res. 1997;15(3):427-36.

38. Roux PP, Barker PA. Neurotrophin signaling through the p75 neurotrophin receptor. Prog Neurobiol. 2002;67(3):203-33.

39. Milgrom C, Novack V, Weil Y, Jaber S, Radeva-Petrova DR, Finestone A. Risk factors for idiopathic frozen shoulder. Isr Med Assoc J. 2008;10(5):361-4.

40. Huang YP, Fann CY, Chiu YH, Yen MF, Chen LS, Chen $\mathrm{HH}$, et al. Association of diabetes mellitus with the risk of developing adhesive capsulitis of the shoulder: a longitudinal population-based follow up study. Arthritis Care Res (Hoboken). 2013;65(7):1197-202.

41. Pobiel RS, Schellhas KP, Eklund JA, Golden MJ, Johnson BA, Chopra S, et al. Selective cervical nerve root blockade: prospective study of immediate and longer term complications. AJNR Am J Neuroradiol. 2009;30(3):507-11.

42. Nash TP. Comment on 'A cervical anterior spinal artery syndrome after diagnostic blockade of the right C6-nerve root'. PJAM Brouwers et al., PAIN. 2001;91:397-9.

43. Rozin L, Rozin R, Koehler SA, Shakir A, Ladham S, Barmada $\mathrm{M}$, et al. Death during transforaminal epidural steroid nerve root block (C7) due to perforation of the left vertebral artery. Am J Forensic Med Pathol. 2003;24:351-5.

44. Hamdan TA, Al-Essa KA. Manipulation under anaesthesia for the treatment of frozen shoulder. Int Orthop. 2003;27(2):107-9.

45. Loew M, Heichel TO, Lehner B. Intraarticular lesions in primary frozen shoulder after manipulation under general anesthesia. J Should Elb Surg. 2005;14(1):16-21. 
46. Magnussen RA, Taylor DC. Glenoid fracture during manipulation under anesthesia for adhesive capsulitis: a case report. J Shoulder Elb Surg. 2011;20(3):e23-6.

47. Ding H, Tang Y, Xue Y, Yang Z, Li Z, He D, et al. A report on the prevalence of depression and anxiety in patients with frozen shoulder and their relations to disease status. Psychol Health Med. 2014;19(6):730-7.

48. Huang SW, Lin JW, Wang WT, Wu CW, Liou TH, Lin HW. Hyperthyroidism is a risk factor for developing adhesive capsulitis of the shoulder: a nationwide longitudinal population-based study. Sci Rep. 2014;25(4):4183. 